\title{
Minimally-Myelosuppressive Asparaginase-Containing Induction Regimen for Treatment of a Jehovah's Witness with mutant IDH1/NPM1/NRAS Acute Myeloid Leukemia
}

\author{
Ashkan Emadi ${ }^{1, *}$, Najeebah A. Bade ${ }^{1}$, Brandi Stevenson ${ }^{1}$ and Zeba Singh ${ }^{2}$ \\ 1 School of Medicine, Marlene \& Stewart Greenebaum Cancer Center, University of Maryland, \\ 22 South Greene Street, Room N9E24, Baltimore, MD 21201, USA; nabade@gmail.com (N.A.B.); \\ bstevenson@umm.edu (B.S.) \\ 2 Department of Pathology, School of Medicine, University of Maryland, Baltimore, MD 21201, USA; \\ zsingh@umm.edu \\ * Correspondance: aemadi@umm.edu; Tel.: +1-410-328-2596; Fax: +1-410-328-6896
}

Academic Editor: Dhimant Desai

Received: 13 January 2016; Accepted: 8 March 2016; Published: 10 March 2016

\begin{abstract}
Treatment of patients with acute myeloid leukemia (AML) who do not wish to accept blood product transfusion, including Jehovah's Witnesses, is extremely challenging. The use of conventional chemotherapy for induction of complete remission (CR) results in profound anemia and thrombocytopenia requiring frequent transfusions of blood products, without which such treatment will be life-threatening. Finding a well tolerable, minimally myelosuppressive induction regimen for such patients with AML is a clear example of area of unmet medical need. Here, we report a successful treatment of a 52-year-old Jehovah's Witness with newly diagnosed AML with peg-asparaginase, vincristine and methylprednisolone. The AML was characterized with normal karyotype, and mutations in isocitrate dehydrogenase 1 (IDH1-Arg132Ser), nucleophosmin 1 (NPM1-Trp289Cysfs*12) and neuroblastoma RAS viral oncogene homolog (NRAS-G1y12Va1). After one 28-day cycle of treatment, the patient achieved complete remission with incomplete count recovery (CRi) and after the second cycle, he achieved CR with full blood count recovery. The patient has never received any blood products. Notwithstanding that myeloperoxidase-induced oxidative degradation of vincristine results in its lack of activity as monotherapy in AML, its combination with corticosteroid and asparaginase has resulted in a robust remission in this patient. Diminished steroid clearance by asparaginase activity as well as reduction in serum glutamine level induced by glutaminase enzymatic activity of asparaginase may have contributed to effective killing of the myeloblasts that carry IDH1/NPM1/NRAS mutations. In conclusion, asparaginase-containing regimens, which are approved for treatment of acute lymphoblastic leukemia (ALL) but not AML, can be used to treat patients with AML who do not accept blood transfusion.
\end{abstract}

Keywords: acute myeloid leukemia (AML); isocitrate dehydrogenase (IDH); asparaginase

\section{Introduction}

Treatment of individuals who do not accept transfusion of blood products, including Jehovah's Witnesses, with acute myeloid leukemia (AML) is exceptionally challenging [1-3]. Conventional remission induction regimens containing cytotoxic agents such as cytarabine and anthracyclines often are not offered to these patients, because chemotherapy results in profound myelosuppression requiring frequent red blood cell and platelet transfusions without which severe anemia and 
thrombocytopenia are life-threatening [4-6]. On the other hand, without induction treatment, these patients rapidly will succumb to their leukemia.

Asparaginase products, which are approved for treatment of acute lymphoblastic leukemia (ALL) [7-9], but not AML, do not suppress the bone marrow and can provide a treatment option for patients with AML who do not wish to receive blood transfusion [10,11]. In this article, we report and discuss a successful treatment of a Jehovah's Witness with newly diagnosed AML with an asparaginase-containing regimen.

\section{Case Report}

A 52-year-old Jehovah's Witness presented with a few weeks of fatigue, weight loss, and pancytopenia; white-cell count (WBC) $7.3 \times 10^{9} / \mathrm{L}$ with $57 \%$ peripheral blast, hemoglobin $6.2 \mathrm{~g} / \mathrm{dL}$, platelet $64 \times 10^{9} /$ L. Bone marrow aspiration and biopsy confirmed the diagnosis of AML (Figure 1A,B).
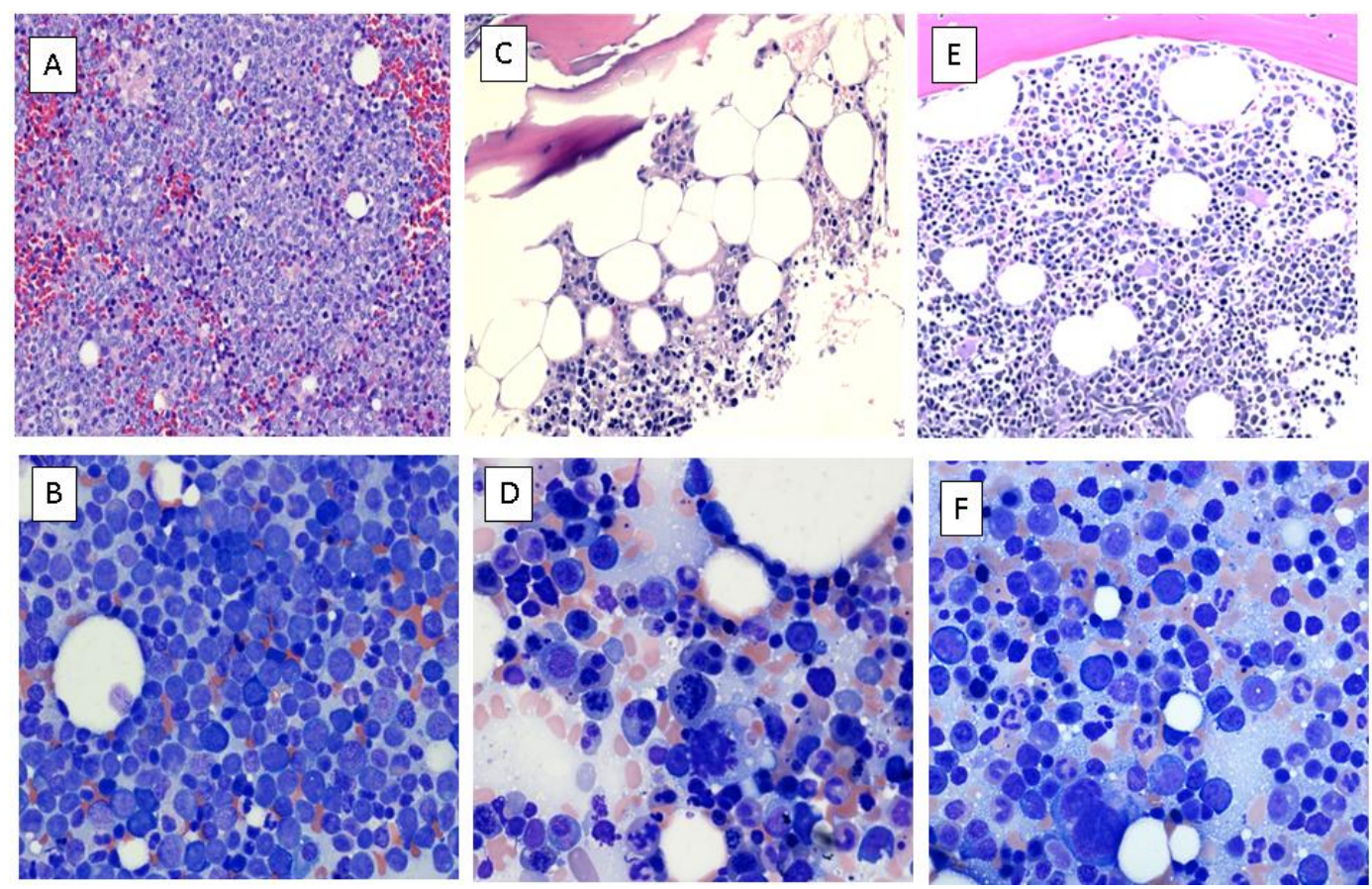

Figure 1. Bone marrow aspirate, biopsy and clot section smears. (A) Clot section at diagnosis (Hematoxylin and Eosin [H\&E] stain $\times 20$ ) showing large hypercellular marrow fragments (cellularity $>90 \%$ ) with predominantly blasts (70\%) admixed with maturing erythroid precursors and lymphocytes. Megakaryocytes are identified, but decreased in proportion to the cellularity. Maturing granulopoiesis is markedly reduced; (B) Bone marrow aspirate at diagnosis (Wright stain $\times 40$ ) showing myeloid:erythroid (M:E) ratio of 3:1, markedly reduced and left-shifted granulopoiesis, blasts comprising $52 \%$ of the cellularity; (C) Bone marrow core biopsy on day 28 (H\&E stain $\times 20$ ) showing maturing erythroid precursors as the majority of the cells, lymphocytes, and a few megakaryocytes with decreased granulopoiesis and no overt increase in blasts; (D) Bone marrow aspirate on day 28 (Wright stain $\times 40$ ) showing decreased M:E ratio (0.5:1), most of the cells being of erythroid lineage and lymphocytes with a few maturing granulocytes and mildly dysplastic megakaryocytes related to chemotherapy and no increase in blast cells; (E) Bone marrow core biopsy on day 81 (H\&E stain $\times 20$ ) showing normocellular $(50 \%-60 \%)$ marrow for the age of the patient, maturing granulopoiesis and erythropoiesis with an erythroid predominance, adequate megakaryocytes focally clustered with occasional small forms, no lymphoid aggregates, and no myeloblasts; (F) Bone marrow aspirate on day 81 (Wright stain $\times 40$ ) showing M:E ratio of 0.8:1, full spectrum maturation in the granulocytic and erythroid series, megakaryocytes with normal morphology, no increase in lymphocytes, plasma cells, or presence of any other abnormal cell population including no increase in blasts. 
Immunophenotypic studies by flow cytometry on the bone marrow specimen showed $60 \%-70 \%$ blasts expressing CD117 (heterogeneous), CD33, CD13, CD15 (partial), CD11b (heterogeneous), CD11c, CD38, CD64 (partial), CD71 (partial), and myeloperoxidase. The blasts were negative for CD34, HLA-DR, CD14, CD16, CD56, TdT, and all T- and B-lymphoid antigens. Chromosome analysis revealed 46XY in 20 metaphase cells. Mutational analysis of the DNA from bone marrow blasts revealed mutations in isocitrate dehydrogenase 1 (IDH1-Arg132Ser, nucleotide change: c.394C > A, mutation level: 50\%), nucleophosmin 1 (NPM1-Trp289Cysfs*12, nucleotide change: c.860_863dupTCTG, mutation level: 41\%) and neuroblastoma RAS viral oncogene homolog (NRAS-G1y12Va1, nucleotide change: $0.35 \mathrm{G}>\mathrm{T}$, mutation level: $27 \%$ ). Due to religious belief, the patient did not accept transfusion of red blood cells, platelets or other blood products but wished to proceed with treatment. After a comprehensive discussion of risks and benefits with the patient and his family, a minimally myelosuppressive treatment with peg-asparaginase ( 2500 units $/ \mathrm{m}^{2}$ intravenously on day 8 ), vincristine ( $2 \mathrm{mg}$ intravenously on days $1,6,11,16,21,26)$ and methylprednisolone $\left(20 \mathrm{mg} / \mathrm{m}^{2}\right.$ twice daily on days 1-28) was initiated [11].

He tolerated the chemotherapy regimen well without developing any major adverse events. Even though, his hemoglobin and platelet counts remained low (Figure 2), he did not experience any symptoms indicating cardio-respiratory compromise or any bleeding, and did not receive any blood product transfusion.
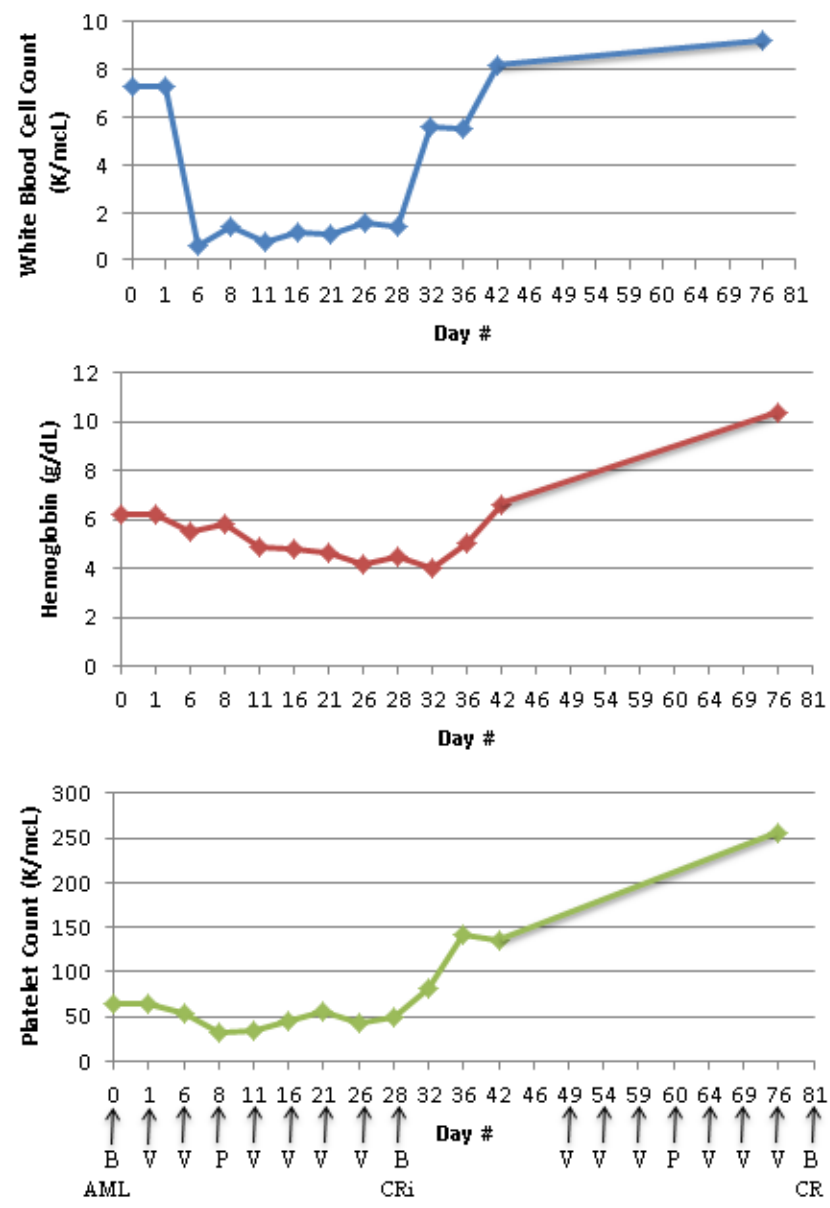

Figure 2. White blood cell, hemoglobin, and platelet counts from diagnosis throughout two cycles of chemotherapy regimens; Arrows indicate the days of bone marrow biopsy (B), receiving vincristine $(\mathrm{V})$, or pegasparaginase $(\mathrm{P})$. 
Twenty eight days after initiation of the chemotherapeutic agents, a bone marrow aspiration and biopsy was repeated which showed cellular marrow with no morphological or immunophenotypic evidence of AML (Figure 1C,D) with a decrease in blasts from $55 \%$ by flow cytometry to $<1 \%$. On the same day, complete blood count (CBC) showed WBC $1.4 \times 10^{9} / \mathrm{L}$ with $53 \%$ granulocyte, no blasts, hemoglobin $4.5 \mathrm{~g} / \mathrm{dL}$, and platelet $50 \times 10^{9} / \mathrm{L}$ (Figure 2), confirming the achievement of complete remission with incomplete count recovery (CRi). Due to logistical issues including insurance coverage, serum glutamine and 2-hydroxyglutarate (2-HG) levels could not be measured.

One week later, the patient developed edema in the right upper extremity where had a peripherally inserted central catheter (PICC) as well as left lower extremity edema. The duplex ultrasound revealed acute thrombus in the right distal subclavian vein, right axillary vein and right brachial vein as well as acute, occlusive deep venous thrombosis (DVT) of the paired left peroneal veins (isolated, axial calf DVT) without extension proximally into the left popliteal vein or the more-proximal deep veins of the left leg. Since at this point patient had adequate platelet recovery to $142 \times 10^{9} / \mathrm{L}$, he was treated with full dose low molecular weight heparin. His symptoms had resolved in a few days.

Forty nine days after diagnosis and initiation of the first cycle of induction treatment, he began the second cycle of the same chemotherapy regimen with pegasparaginase, vincristine, and prednisone (50\% dose reduced) as an outpatient. Patient remained on anticoagulation and tolerated the chemotherapy well except for development of Grade 2 vincristine-induced peripheral neuropathy. The CBC upon completion of the second cycle showed WBC $9.2 \times 10^{9} / \mathrm{L}$ with $54 \%$ granulocytes, no blasts, hemoglobin $10.4 \mathrm{~g} / \mathrm{dL}$, and platelets $255 \times 10^{9} / \mathrm{L}$ (Figure 2). His bone marrow aspiration and biopsy revealed normocellular bone marrow for age (cellularity 50\%-60\%) with full-spectrum trilineage hematopoiesis, and no morphological or immunophenotypic evidence of involvement by AML, confirming the achievement of CR (Figure 1E,F). The re-analysis of the bone marrow cells for the myeloid mutation panel revealed no somatic mutations or disease specific alterations, including the original IDH1, NPM1, and NRAS indicating achievement of molecular remission. His performance status and organ functions have remained normal.

\section{Discussion}

Both E. coli and Erwinia-derived asparaginase products including long acting pegasparaginase (polyethylene glycol L-asparaginase) possess a dual asparaginase and glutaminase enzymatic activity that diminishes both serum asparagine and glutamine levels by deamidating them to aspartate and glutamate, respectively [12]. It is believed that the cytotoxicity of asparaginase against lymphoblasts is due to auxotrophic nature of these cells for asparagine; however, the therapeutic value of asparaginases against myeloblasts is reported to be due to glutamine depletion resulting in disruption of protein synthesis downstream of mammalian target of rapamycin (mTOR) causing strong apoptotic and autophagic responses [13-16].

Mutations in IDH1 and IDH2 have been reported in approximately $20 \%$ of de novo AML [17-21], and their presence is an unfavorable prognostic factor according to most studies [22-26]. It has been suggested that IDH mutations confer adverse prognostic effect in patients with AML whose myeloblasts lack NPM1 mutation [26,27]. Wild-type IDHs are NADP-dependent enzymes that catalyze the oxidative decarboxylation of isocitrate to $\alpha$-ketoglutarate $(\alpha-K G)$, with production of NADPH [28]. Altered amino acids in mutant IDH are located in the catalytic pocket of the enzymes resulting in converting $\alpha-\mathrm{KG}$ to 2-hydroxyglutarate (2-HG) with the consumption of NADPH. Heterozygous mutations resulting in a single amino acid change at arginine 132 (R132H, R132C, R132G, R132S) of IDH1 and arginine 140 (R140Q, R140W) or arginine 172 (R172K, R172G) of IDH2 have been reported $[18,20]$. By ${ }^{13} \mathrm{C}$ and isotope-labeling experiments, it has been shown that the primary source for $\alpha-K G$ in AML cells with IDH mutation is glutamine [18]. Subsequently, it has been demonstrated that in vitro interruption of glutamine metabolism preferentially slows the growth of primary AML cells with mutant IDH versus wild type IDH $[29,30]$. Clinical studies aiming at the evaluation of 
safety and efficacy of asparaginase products in patients with AML with or without IDH mutations are ongoing (NCT02283190 and NCT01810705).

The major adverse events of asparaginase products, reported from clinical trials involving patients with ALL, include anaphylaxis and serious allergic reactions, thrombosis, pancreatitis, glucose intolerance, coagulopathy, and hepatotoxicity. Interestingly, myelosuppression does not occur frequently and seriously after asparaginase administration. Also the myelosuppressive effect of vincristine compared to other conventional chemotherapeutic agents is minimal.

The fact that asparaginase and vincristine are minimally myelosuppressive is important for patients such as Jehovah's Witnesses that do not accept blood product transfusion; as it is well known that the use of conventional chemotherapy for remission induction in AML results in life-threatening anemia and thrombocytopenia, requiring blood product transfusions with an average of 10.8 and 8.5 units of red blood cell and platelet transfusions, respectively [31]. We combined asparaginase and steroid with vincristine to increase their anti-leukemic effect, while maintaining the minimal myelosuppressive property of the regimen. Vincristine, a cell cycle-specific vinca alkaloid which induces metaphase arrest, as a single agent is not active against myeloblasts in AML [32]. Overexpression of multi-drug resistance proteins and myeloperoxidase-induced oxidation and degradation of vincristine are the main causes of inherent resistance of AML cells to vincristine as monotherapy [33,34]. While a synergistic or additive anti-leukemic activity between vincristine and asparaginase is not well known; decreased clearance of steroid with sustained asparaginase activity combined with prolonged asparaginase half-life due to immunomodulatory effect of steroid on anti-asparaginase antibody suggest synergism between asparaginase and steroid products [35,36].

\section{Conclusion}

A minimally myelosuppressive regimen including pegasparaginase, vincristine and steroid was used to induce durable complete remission in a patient with mutant IDH1/NPM1/NRAS AML who did not want to receive blood product transfusions. Moving forward, we plan to continue using non-myelosuppressive mono- or combination-therapies as consolidation regimens for this patient. We also plan to prospectively test the effect of this combination for similar patients with prospective measurement of serum biomarkers.

Acknowledgments: We would like to thank physicians, nurses, and staff of the University of Maryland Greenebaum Cancer Center who are contributing to the care of the patient.

Author Contributions: Ashkan Emadi and Najeebah A. Bade conceived and designed the treatment plan, analyzed the data and wrote the paper; Brandi Stevenson significantly participated in coordination of the care of this patient and wrote the paper; Zeba Singh conducted and interpreted the pathological studies and wrote the paper. Authorship must be limited to those who have contributed substantially to the work reported. All authors have read and approved the final manuscript.

Conflicts of Interest: The authors declare no conflict of interest.

\section{References}

1. Kerridge, I.; Lowe, M.; Seldon, M.; Enno, A.; Deveridge, S. Clinical and ethical issues in the treatment of a jehovah's witness with acute myeloblastic leukemia. Arch. Intern. Med. 1997, 157, 1753-1757. [CrossRef] [PubMed]

2. Cullis, J.O.; Duncombe, A.S.; Dudley, J.M.; Lumley, H.S.; Apperley, J.F.; Smith, A.G. Acute leukaemia in jehovah's witnesses. Br. J. Haematol. 1998, 100, 664-668. [CrossRef] [PubMed]

3. Brown, N.M.; Keck, G.; Ford, P.A. Acute myeloid leukemia in jehovah witnesses. Leuk. Lymphoma 2008, 49, 817-820. [CrossRef] [PubMed]

4. Emadi, A.; Karp, J.E. The state of the union on treatment of acute myeloid leukemia. Leuk. Lymphoma 2014, 55, 2423-2425. [CrossRef] [PubMed]

5. Emadi, A.; Karp, J.E. The clinically relevant pharmacogenomic changes in acute myelogenous leukemia. Pharmacogenomics 2012, 13, 1257-1269. [CrossRef] [PubMed] 
6. Bhatnagar, B.; Duong, V.H.; Gourdin, T.S.; Tidwell, M.L.; Chen, C.; Ning, Y.; Emadi, A.; Sausville, E.A.; Baer, M.R. Ten-day decitabine as initial therapy for newly diagnosed patients with acute myeloid leukemia unfit for intensive chemotherapy. Leuk. Lymphoma 2014, 55, 1533-1537. [CrossRef] [PubMed]

7. F.D.A. Label for asparaginase. Available online: http://www.accessdata.fda.gov/drugsatfda_docs/label/ 2013/101063s5169lbl.pdf (accessed on 3 March 2016).

8. F.D.A. Label for erwinaze. Available online: http://www.accessdata.fda.gov/drugsatfda_docs/label/2011/ 125359lbl.pdf (accessed on 3 March 2016).

9. F.D.A. Label for oncaspar. Available online: http://www.accessdata.fda.gov/drugsatfda_docs/label/2014/ 103411s5180lbl.pdf (accessed on 3 March 2016).

10. Emadi, A.; Zokaee, H.; Sausville, E.A. Asparaginase in the treatment of non-all hematologic malignancies. Cancer Chemother. Pharmacol. 2014, 73, 875-883. [CrossRef] [PubMed]

11. Fujita, H.; Iguchi, M.; Tachibana, T.; Takemura, S.; Taguchi, J.; Tanaka, M.; Maruta, A.; Ishigatsubo, Y. Remission induction treatment for 6 patients of jehova's witnesses with de novo acute leukemia. Blood 2006, 108, 217B-218B.

12. Avramis, V.I. Asparaginases: A successful class of drugs against leukemias and lymphomas. J. Pediatr. Hematol. Oncol. 2011, 33, 573-579. [CrossRef] [PubMed]

13. Willems, L.; Jacque, N.; Jacquel, A.; Neveux, N.; Maciel, T.T.; Lambert, M.; Schmitt, A.; Poulain, L.; Green, A.S.; Uzunov, M.; et al. Inhibiting glutamine uptake represents an attractive new strategy for treating acute myeloid leukemia. Blood 2013, 122, 3521-3532. [CrossRef] [PubMed]

14. Samudio, I.; Konopleva, M. Asparaginase unveils glutamine-addicted aml. Blood 2013, 122, 3398-3400. [CrossRef] [PubMed]

15. Jacque, N.; Ronchetti, A.M.; Larrue, C.; Meunier, G.; Birsen, R.; Willems, L.; Saland, E.; Decroocq, J.; Thiago, T.T.; Lambert, M.; et al. Targeting glutaminolysis has antileukemic activity in acute myeloid leukemia and synergizes with bcl-2 inhibition. Blood 2015, 126, 1346-1356. [CrossRef] [PubMed]

16. Emadi, A. Exploiting aml vulnerability: Glutamine dependency. Blood 2015, 126, 1269-1270. [CrossRef] [PubMed]

17. Mardis, E.R.; Ding, L.; Dooling, D.J.; Larson, D.E.; McLellan, M.D.; Chen, K.; Koboldt, D.C.; Fulton, R.S.; Delehaunty, K.D.; McGrath, S.D.; et al. Recurring mutations found by sequencing an acute myeloid leukemia genome. New Engl. J. Med. 2009, 361, 1058-1066. [CrossRef] [PubMed]

18. Dang, L.; White, D.W.; Gross, S.; Bennett, B.D.; Bittinger, M.A.; Driggers, E.M.; Fantin, V.R.; Jang, H.G.; Jin, S.; Keenan, M.C.; et al. Cancer-associated idh1 mutations produce 2-hydroxyglutarate. Nature 2009, 462, 739-744. [CrossRef] [PubMed]

19. Chou, W.C.; Hou, H.A.; Chen, C.Y.; Tang, J.L.; Yao, M.; Tsay, W.; Ko, B.S.; Wu, S.J.; Huang, S.Y.; Hsu, S.C.; et al. Distinct clinical and biologic characteristics in adult acute myeloid leukemia bearing the isocitrate dehydrogenase 1 mutation. Blood 2010, 115, 2749-2754. [CrossRef] [PubMed]

20. Ward, P.S.; Patel, J.; Wise, D.R.; Abdel-Wahab, O.; Bennett, B.D.; Coller, H.A.; Cross, J.R.; Fantin, V.R.; Hedvat, C.V.; Perl, A.E.; et al. The common feature of leukemia-associated idh1 and idh2 mutations is a neomorphic enzyme activity converting alpha-ketoglutarate to 2-hydroxyglutarate. Cancer Cell 2010, 17, 225-234. [CrossRef] [PubMed]

21. The Cancer Genome Atlas Research Network. Genomic and epigenomic landscapes of adult de novo acute myeloid leukemia. New Engl. J. Med. 2013, 368, 2059-2074.

22. Abbas, S.; Lugthart, S.; Kavelaars, F.G.; Schelen, A.; Koenders, J.E.; Zeilemaker, A.; van Putten, W.J.; Rijneveld, A.W.; Lowenberg, B.; Valk, P.J. Acquired mutations in the genes encoding idh1 and idh2 both are recurrent aberrations in acute myeloid leukemia: Prevalence and prognostic value. Blood 2010, 116, 2122-2126. [CrossRef] [PubMed]

23. Marcucci, G.; Maharry, K.; Wu, Y.Z.; Radmacher, M.D.; Mrozek, K.; Margeson, D.; Holland, K.B.; Whitman, S.P.; Becker, H.; Schwind, S.; et al. IDH1 and IDH2 gene mutations identify novel molecular subsets within de novo cytogenetically normal acute myeloid leukemia: A cancer and leukemia group $\mathrm{b}$ study. J. Clin. Oncol. 2010, 28, 2348-2355. [CrossRef] [PubMed]

24. Paschka, P.; Schlenk, R.F.; Gaidzik, V.I.; Habdank, M.; Kronke, J.; Bullinger, L.; Spath, D.; Kayser, S.; Zucknick, M.; Gotze, K.; et al. IDH1 and IDH2 mutations are frequent genetic alterations in acute myeloid leukemia and confer adverse prognosis in cytogenetically normal acute myeloid leukemia with npm1 mutation without flt3 internal tandem duplication. J. Clin. Oncol. 2010, 28, 3636-3643. [CrossRef] [PubMed] 
25. Zou, Y.; Zeng, Y.; Zhang, D.F.; Zou, S.H.; Cheng, Y.F.; Yao, Y.G. IDH1 and IDH2 mutations are frequent in chinese patients with acute myeloid leukemia but rare in other types of hematological disorders. Biochem. Biophys. Res. Commun. 2010, 402, 378-383. [CrossRef] [PubMed]

26. Patel, J.P.; Gonen, M.; Figueroa, M.E.; Fernandez, H.; Sun, Z.; Racevskis, J.; Van Vlierberghe, P.; Dolgalev, I.; Thomas, S.; Aminova, O.; et al. Prognostic relevance of integrated genetic profiling in acute myeloid leukemia. New Engl. J. Med. 2012, 366, 1079-1089. [CrossRef] [PubMed]

27. Yamaguchi, S.; Iwanaga, E.; Tokunaga, K.; Nanri, T.; Shimomura, T.; Suzushima, H.; Mitsuya, H.; Asou, N. IDH1 and IDH2 mutations confer an adverse effect in patients with acute myeloid leukemia lacking the npm1 mutation. Eur. J. Haematol. 2014, 92, 471-477. [CrossRef] [PubMed]

28. Xu, X.; Zhao, J.; Xu, Z.; Peng, B.; Huang, Q.; Arnold, E.; Ding, J. Structures of human cytosolic nadp-dependent isocitrate dehydrogenase reveal a novel self-regulatory mechanism of activity. J. Biol. Chem. 2004, 279, 33946-33957. [CrossRef] [PubMed]

29. Emadi, A.; Jun, S.A.; Tsukamoto, T.; Fathi, A.T.; Minden, M.D.; Dang, C.V. Inhibition of glutaminase selectively suppresses the growth of primary acute myeloid leukemia cells with idh mutations. Exp. Hematol. 2014, 42, 247-251. [CrossRef] [PubMed]

30. Fathi, A.T.; Wander, S.A.; Faramand, R.; Emadi, A. Biochemical, epigenetic, and metabolic approaches to target idh mutations in acute myeloid leukemia. Semin. Hematol. 2015, 52, 165-171. [CrossRef] [PubMed]

31. Jansen, A.J.; Caljouw, M.A.; Hop, W.C.; van Rhenen, D.J.; Schipperus, M.R. Feasibility of a restrictive red-cell transfusion policy for patients treated with intensive chemotherapy for acute myeloid leukaemia. Transfus. Med. 2004, 14, 33-38. [CrossRef] [PubMed]

32. Schlaifer, D.; Cooper, M.R.; Attal, M.; Sartor, A.O.; Trepel, J.B.; Laurent, G.; Myers, C.E. Myeloperoxidase: An enzyme involved in intrinsic vincristine resistance in human myeloblastic leukemia. Blood 1993, 81, 482-489. [PubMed]

33. McGrath, T.; Center, M.S. Mechanisms of multidrug resistance in hl60 cells: Evidence that a surface membrane protein distinct from p-glycoprotein contributes to reduced cellular accumulation of drug. Cancer Res. 1988, 48, 3959-3963. [CrossRef]

34. Ozgen, U.; Savasan, S.; Stout, M.; Buck, S.; Ravindranath, Y. Further elucidation of mechanism of resistance to vincristine in myeloid cells: Role of hypochlorous acid in degradation of vincristine by myeloperoxidase. Leukemia 2000, 14, 47-51. [CrossRef] [PubMed]

35. Yang, L.; Panetta, J.C.; Cai, X.; Yang, W.; Pei, D.; Cheng, C.; Kornegay, N.; Pui, C.H.; Relling, M.V. Asparaginase may influence dexamethasone pharmacokinetics in acute lymphoblastic leukemia. J. Clin. Oncol. 2008, 26, 1932-1939. [CrossRef] [PubMed]

36. Kawedia, J.D.; Liu, C.; Pei, D.; Cheng, C.; Fernandez, C.A.; Howard, S.C.; Campana, D.; Panetta, J.C.; Bowman, W.P.; Evans, W.E.; et al. Dexamethasone exposure and asparaginase antibodies affect relapse risk in acute lymphoblastic leukemia. Blood 2012, 119, 1658-1664. [CrossRef] [PubMed] 